\title{
Precision genetic cellular models identify therapies protective against endoplasmic reticulum stress
}

\section{Summary sentence}

Novel drug screening modality identifies compounds that correct aberrant molecular phenotypes in precision cellular models of glycosylation defects.

Irina V. Lebedeva ${ }^{1}$, Michelle V. Wagner ${ }^{2,3}$, Sunil Sahdeo ${ }^{2,3}$, Yi-Fan Lu ${ }^{1}$, Anuli Anyanwu-Ofili ${ }^{4}$, Matthew B. Harms $^{5}$, Jehangir S. Wadia ${ }^{2,3}$, Gunaretnam Rajagopal ${ }^{4}$, Michael J. Boland ${ }^{1,5 *}$, David B. Goldstein ${ }^{1,6 *}$

${ }^{1}$ Institute for Genomic Medicine, Columbia University Irving Medical Center, New York, NY

${ }^{2}$ Janssen Prevention Center, Janssen Pharmaceutical Companies of Johnson \& Johnson, San Diego, CA

${ }^{3}$ Janssen R\&D US, San Diego, CA

${ }^{4}$ Discovery Sciences, Janssen R\&D, Spring House, PA

${ }^{5}$ Department of Neurology, Columbia University Irving Medical Center, New York, NY

${ }^{6}$ Department of Genetics and Development, Columbia University Irving Medical Center, New York, NY

Correspondence: M.J.B. mb4129@,columbia.edu, D.B.G. dg2875@columbia.edu

\begin{abstract}
Congenital disorders of glycosylation (CDG) and deglycosylation (CDDG) are a collection of rare pediatric disorders with symptoms that range from mild to life threatening. They typically affect multiple organ systems and usually present with neurological abnormalities including hypotonia, cognitive impairment, and intractable seizures. Several genes have been implicated in the thirty-six types of CDG, but currently NGLY1 is the only known CDDG gene. A common biological mechanism among CDG types and in CDDG is endoplasmic reticulum (ER) stress. Here, we develop two isogenic human cellular models of CDG (PMM2, the most prevalent type of CDG, and $D P A G T 1)$ and of the only CDDG (NGLY1) in an effort to identify drugs that can alleviate ER stress. Systematic phenotyping identified elevated ER stress and autophagy levels among other cellular and morphological phenotypes in each of the cellular models. We screened a complex drug library for compounds able to correct aberrant morphological phenotypes in each of the models using an agnostic phenotypic cell painting assay based on $>300$ cellular features. The image-based screen identified multiple candidate compounds able to correct aberrant morphology, and we show a subset of these are able to correct cellular and molecular defects in each of the models. These results provide new directions for the treatment of rare diseases of glycosylation and deglycosylation and a framework for new drug screening paradigms for more common neurodegenerative diseases characterized by ER stress.
\end{abstract}

\section{Introduction}

Numerous diseases affecting both the central and peripheral nervous system involve elevated endoplasmic reticulum (ER) stress $(1,2)$. In particular, ER stress has been implicated in diseases including Parkinson's disease, Alzheimer's disease, and Amyotrophic Lateral Sclerosis (ALS) (3). This suggests that therapeutic agents that ameliorate the effects of ER stress could have benefits across a broad range of disorders. While screens to identify such agents in the context of complex neurodegenerative diseases are challenging to implement, the etiology of a number of monogenic diseases is in large part attributed to ER stress including the congenital disorders of glycosylation (CDG) and deglycosylation (CDDG) (4-6). Of particular interest, mutations in $P M M 2$, the gene that encodes the cytosolic enzyme phosphomannomutase 2, result in the most common CDG, PMM2-CDG (7). Studies suggest that in PMM2-CDG, cells with weaker ER stress responses are more vulnerable to damage than cells with stronger ER stress responses $(8)$. Moreover, mutations in 
DPAGT1, which encodes the target of the well-known ER stress inducer tunicamycin (9) result in another CDG with multisystemic phenotypes $(10,11)$.

Here we utilize a morphological profiling and screening paradigm to identify agents that protect against the cellular stresses resulting from CDG and CDDG causal mutations. We focus specifically on mutations in $P M M 2$ and DPAGT1, and in NGLY1, which causes the only reported CDDG (6). We used genetic engineering to generate clinically relevant CDG and CDDG genotypes in a karyotypically normal human cell line (hTERT RPE-1) in order to create cellular models amenable to mutation-specific phenotype identification. The hTERT RPE-1 line was selected to allow for morphology-based high content imaging screens to identify phenotypes that are consequences of ER stress. These CDG and CDDG cell lines were used in high-content small molecule screens to identify compounds that revert the imaging phenotypes caused by these mutations. Specifically, we selected 1049 annotated compounds for screening representing a broad chemical space and multiple target classes. In order to validate the performance of the screen, we selected 16 compounds that were ranked amongst the best at phenotype reversion in the screen (protective compounds) and 10 compounds that did not affect aberrant phenotypes (non-active negative control compounds). We then evaluated these compounds in assays designed to test how well they revert mutational phenotypes in our three cellular models.

\section{Results}

Establishment of precise human cellular models of CDG and CDDG

Genome editing was used to generate hTERT RPE-1 cell lines that mimic genotypes associated with CDG and CDDG (Table 1). All known CDDG patients possess complete loss of function of NGLY1 (6). We designed gRNAs to generate the recurrent $N G L Y 1$ R401X missense variant, but after repeated attempts were unable to obtain the homozygous R401X genotype. Therefore, we screened clones for knock-out of NGLY1 resulting from biallelic indel formation $\left(N G L Y 1^{-/-}\right)$. PMM2-CDG often results from compound heterozygous mutations that reduce enzymatic activity $(4,12,13)$. Compound heterozygous $P M M 2$ lines were generated by monoallelic knock-in of the second most recurrent and very severe mutation $(\mathrm{F} 119 \mathrm{~L})(7,14)$, and then screening for an indel on the second allele $\left(P M M 2^{\mathrm{F} 119 \mathrm{~L} /-}\right)$. We generated $D P A G T 1^{+/-}$lines by monoallelic knockout via indel formation. All genotypes were confirmed by Sanger sequencing (Figure 1A, Supplementary Figure 1, Supplementary Table 1).

As expected, $N G L Y 1^{-/-}$lines do not express NGLY1 protein and the levels of PMM2 in $P M M 2^{\mathrm{F} 119 \mathrm{~L} /-}$ were decreased by $\sim 50 \%$ (Figure 1B-C, Supplementary Figure 1). The expression level of DPAGT1 was different between the two DPAGT1 $1^{+/}$clones analyzed despite confirmation of monoallelic disruption of DPAGT1 (Figure 1C and Supplementary Figure 1). Clone DD5, however, consistently expressed $\sim 50 \%$ of DPAGT1 relative to parental cells. This clone was used in the high-content screens discussed below.

Consistent with published studies $(15,16)$, we found DPAGT1 localized to the perinuclear space, and PMM2 was diffuse throughout the cytosol and nucleus (Figure 1E-F, Supplementary Figure 1). Interestingly, PMM2 ${ }^{\text {F119L }}$ was found in cytosolic puncta suggestive of protein aggregation (Figure 1E). We failed to detect NGLY1 by immunocytochemistry using multiple NGLY1 antibodies (not shown).

\section{$C D G$ and $C D D G$ lines exhibit elevated ER stress and autophagy responses}

Although a common molecular feature of CDG is elevated levels of ER stress (17), systematic examination of ER stress in CDDG has not been performed. In order to establish the ER stress profiles of the cellular models, we first established a baseline in isogenic RPE-1 cells using a moderate concentration of the N-linked glycosylation inhibitor and ER stress inducer tunicamycin $(18,19)$ and the ER stress inhibitor salubrinal $(20)$. We chose tunicamycin to activate the ER stress response because it is known to inhibit DPAGT1 (9). We examined ER stress using markers from each of the three recognized pathways of ER stress (Figure 2A): 1) detection of eIF2 $\alpha$ Ser51 phosphorylation (peIF2 $\alpha$ ) and nuclear translocation of ATF4 (CHOP), 2) presence of spliced XBP1 mRNA (sXBP1), and 3) cleavage of $\operatorname{ATF6}(19,21)$. As expected, tunicamycin treatment resulted in strong induction of peIF $2 \alpha$, elevated expression of $\mathrm{s} X B P 1$, and reduced levels of ATF6 (Figure 2C-E, TNM). 
CDG mutations are predicted to result in chronic ER stress (17). Indeed, all CGD and CDDG lines exhibited induction of increased ER stress relative to untreated RPE-1 (Figure 2B-E), but the distinct genotypes showed differential activation of the key ER stress response pathways. For example, $N G L Y 1^{-/-}$and $D P A G T 1^{+/-}$ lines exhibited activation of all three established ER stress pathways, whereas $P M M 2^{\mathrm{F} 119 \mathrm{~L} /-}$ had only significant increases in XBP1 splicing (Figure 2). In fact, the only pathway induced across all CDG and CDDG lines was splicing of $X B P 1$. Low, but significant, levels of apoptosis were detected in $P M M 2^{\mathrm{F} 119 \mathrm{~L} /-}$ and $N G L Y 1^{-/-}$but not in $D P A G T 1^{+/-}$lines. Apoptosis levels in mutant cell lines were much lower as would expected from high ER stress (Supplementary Figure 2B-C) further suggesting that CDG and CDDG lines exhibit lower chronic ER stress responses.

Autophagy is known to play an important role in the response to ER stress and is it seen as a marker of chronic ER stress (22). Significant upregulation of autophagy was detected in all mutant cell lines using a cationic amphiphilic tracer dye that labels autophagic vacuoles (23) by both fluorescent microscopy (Figure 3A) and flow cytometry (Figure 3B). Autophagy induction was also seen with markers of early (p62/SQSTM1) and late (LAMP1) stages of autophagy followed by fluorescent microscopy (Figure 3C-E and Supplementary Figure $3)$.

$C D G$ and $C D D G$ lines exhibit distinctive morphological phenotypes and proliferation defects CDG and CDDG lines were characterized for phenotypes useful for high-content imaging screens. All mutant cell lines exhibited a flat, extended morphology (Figure 4A) reminiscent of cellular senescence that was not seen in the isogenic parental line. Indeed, $\beta$-galactosidase staining confirmed various levels of senescence among the mutant cell lines (Figure 4B, Supplementary Figure 2A). All lines demonstrated slower proliferation compared to the isogenic RPE-1 line (Figure 4C). DPAGT1 $1^{+/-}$lines exhibited the slowest proliferation rates and were comparable to those observed in the parental line when subjected to chronic ER stress from low concentration tunicamycin exposure (Figure 4C).

Primary drug screen identifies compounds able to reverse CDG and CDDG cellular morphology phenotypes Our drug screening platform takes advantage of the distinctive cellular phenotypes that result from the CDG and CDDG mutations. In order to identify compounds able to correct aberrant morphological phenotypes in the mutant lines, we utilized a "cell painting" phenotypic assay $(24,25)$ based on stains for mitochondria, the actin cytoskeleton, endoplasmic reticulum, and nuclei (Figure 5A). Machine learning algorithms were trained on acquired images of RPE-1 cells, and more than 300 cellular features such as fluorescence intensity, presence and numbers of puncta, texture, and cellular shape and geometry were extracted and analyzed. Functional testing and validation of the cell painting assay was performed on CDG and CDDG cell lines (Figure 5B). Importantly, hierarchical clustering and principal component analyses clearly distinguished mutant cells from each other and from parental RPE-1 cells (Figure 5C and D). This demonstrates that there are distinct phenotypic, morphological changes that occur as a consequence of the CDG or CDDG mutation in each of the clones.

We screened 1,049 annotated compounds representing a broad chemical space and multiple target classes on CDG and CDDG cell lines (Figure 6A). The compound library was assembled with publicly available compounds that have known biological activities as well as Janssen proprietary compounds that have evidence of bioactivity compiled from multiple internal data sets. $N G L Y 1^{-/-}, P M M 2^{F 119 L /-}$ and DPAGT1 $1^{+/-}$lines were treated for 24 hours with $10 \mu \mathrm{M}$ of each compound. Parental RPE-1 cells treated with vehicle (DMSO) served as a positive control while vehicle-treated CDG and CDDG lines served as negative controls (Figure 6B). Post-treatment, the cell painting assay was performed and a morphology score was computed for each compound's ability to revert morphology of mutant cell lines toward that of parental cells. Results of the primary morphology screen identified 58 compounds that had positive effects in two or three cell lines (Figure 6B-C). Because CDG/CDDG cell lines demonstrate elevated autophagy levels, primary screening hits were subsequently assessed for their ability to modulate autophagy by immunocytochemistry with LC3 as the marker. Twelve candidate compounds reduced autophagy in all three cell lines (Group I, Supplementary Table 
2), and 10 additional candidate compounds (confirmed in at least 2 cell lines) that had a minimal, or no effect on autophagy (Group II, Supplementary Table 2).

\section{Evaluation of compounds for amelioration of ER stress and proliferation defects}

Top six candidates from each Group I and Group II were further evaluated their ability to alleviate ER stress in the CDG and CDDG lines. Additionally, compounds that improved phenotypes in all three genetic lines were added to the validation list. In order to validate the efficiency and potency of the primary screen, ten non-active compounds in the cell painting assay were selected for comparison to candidate compounds (Table 1). In total, sixteen protective compounds and 10 inactive compounds (Table 1, Supplementary Table 4) were tested for their effects on cell proliferation and $\mathrm{s} X B P 1$ expression. We focused on $\mathrm{s} X B P 1$ expression because it was the only ER stress marker dysregulated across all three models and the only significant ER stress marker in $P M M 2^{\mathrm{F} 119 \mathrm{~L} / \mathrm{s}}$ (Figure 2C-D). Dose response curves on RPE-1 cells identified the lowest non-toxic concentration for candidate compounds (see Methods).

None of the ten non-active control compounds had effects on $\mathrm{s} X B P 1$ expression (Figure 7A-C, grey) or proliferation (Figure 7D-F, grey). In contrast, all active compounds impacted one or both assays in at least one of the cell lines. Compound effects appeared to be mechanism and cell line-dependent in the proliferation and $s X B P 1$ assays. For example, the autophagy inducing compounds (Group II) were more efficient in the CDG lines, while Group I compounds showed effects on all lines (Figure 7 and Table 1). Compounds 1, 3, 4, 5, and 14 decreased $\mathrm{s} X B P 1$ expression in CDDG lines compared to DMSO treated controls (dark grey) but did not effect proliferation (Figure 7A and D). Similarly, there was no correlation between reduction of $\mathrm{s} X B P 1$ expression and repair of proliferation for compounds 3, 4, 5 and 14 in CDG cell lines. Group I candidates 6 and 9 and Group II candidates 15, 25 and 26 all effectively reduced sXBP1 expression (Figure 7A-C), and showed restoration of proliferation in CDG and CDDG lines, (Figure 7D-F). Active compounds, but not non-active controls, were able to revert aberrant cellular morphology similar to that of vehicle treated controls

(Supplementary Figure 4). Together, these data validate the effectiveness of the screen, and identify sets of compounds that are able to correct aberrant cellular phenotypes associated with CDDG and CDG genotypes.

Proton pump inhibitors (PPIs) are a class of drugs that act mainly as irreversible inhibitors of the $\mathrm{H}^{+} / \mathrm{K}^{+}$ATPase pump and have been suggested as potential therapeutics for CDDG (26). We tested whether three PPIs (omeprazole $(\mathrm{OmP})$, rabeprazole $(\mathrm{RbP})$, dexlansoprazole $(\mathrm{DxP})$ ) could alter the cell proliferation deficits and abnormal $\mathrm{s} X B P 1$ expression. We found that all of the PPIs were able to alleviate $\mathrm{s} X B P 1$ expression (Figure 7A$\mathrm{C}$, red), and promote proliferation of CDG and CDDG lines (Figure 7D-F, red). Interestingly, the CDG lines were more responsive to PPIs than the CDDG line.

\section{Discussion}

A central challenge in the development of novel therapies is the development of screenable models that focus on disease relevant phenotypes. Screens based on mutation-induced phenotypes, such as morphological differences, allows one to establish a screening assay without a full understanding of the molecular mechanisms that drive disease pathology. This creates an opportunity for the identification of new therapeutic targets as well as uncovering new insights related to etiology.

The objective of the high-content, phenotypic screen described here was to rapidly identify small molecules capable of alleviating ER stress in cellular models of monogenic disease. The rationale for our screen is that ER stress responses should be applicable across a variety of cell types, and drugs capable of alleviating ER stress will help treat symptoms of disease. Backed by the growing body of evidence linking ER stress to multiple neurological conditions and to CDG and CDDG, we reasoned that using ER stress markers as a functional readout combined with cellular phenotypes can serve as a proxy for overall cellular health on a disease background. It was important to develop the CDDG and CDG models in a cell type with uniform morphology that permits rapid and easily quantifiable morphology changes. We note that a screen in a more disease relevant cell type such as hiPSC-derived neurons may be more applicable; however, such approaches have a number of drawbacks that our approach addresses. For instance, common neuronal differentiation 
methods yield a heterogeneous population of cells with differing levels of maturity and morphology that renders potential molecular or morphological phenotypes difficult to identify or interpret. Moreover, the labor intensiveness and cost of differentiation methods often makes large-scale screens prohibitive. Rather, a multitiered strategy whereby large screens are performed on genetic cellular models with high confidence phenotypes and lead compounds are then validated in more relevant cellular and/or animal models is more efficacious.

A majority of the active compounds in our screen, \#s 3, 4, 6, 9, 15, 25, are reported to affect microtubules (27-40) (Supplementary Table 3) either through direct effects on microtubules themselves or by targeting proteins (e.g. kinases) that regulate microtubule dynamics. Multiple compounds converging on the regulation of microtubules lends support to their involvement in ER stress responses (41). Furthermore, compounds, structurally similar to compound 6, 9, 15, 25 and 26 (see Supplementary Table 4 for structures) are reported to prevent ER stress in multiple cellular systems through inhibition of NADPH oxidase 2 (NOX2) (42), isocitrate dehydrogenase 1 (IDH1) $(43,44)$, various kinases, such as CDK (45-48), JAK1/2 kinases and STAT signaling (49-51), general control nonderepressible 2 (GSN2) kinase $(52,53)$, and growth factor receptor kinases (54-57) (Supplementary Table 3). CDG Type Ia (PMM2-CDG) patients often present with cerebellar atrophy (58), that has been attributed to defective ER stress response (8).

Our study describes, to our knowledge, the first example of a high-throughput screen on genetically modified human cells for three monogenic diseases with a shared endogenous molecular phenotype. Here we focused on a biological process, ER stress, thought to unite a number of genetic and more common diseases, and successfully identified bioactive ER stress diminishing compounds through unbiased morphological screening. This work has shown it is possible to develop cellular models for CDGs that possess screenable phenotypes able to identify compounds that alleviate molecular and morphological phenotypes caused by these genetic conditions, thereby establishing a platform to identify targeted and common treatments for CDDG and CDGs. Due to the genetic heterogeneity of CDGs, it will be important to apply similar analyses to other genetic causes of CDG to determine whether there are compounds that alleviate the ER stress-related symptoms across a wide range of disease. Beyond establishing a paradigm for identifying therapeutic compounds for rare monogenic diseases, this work suggests a direction for identifying compounds able to alleviate the symptoms related to ER stress in more common diseases characterized by ER stress including neurodegenerative diseases.

Loss of microtubule mass or altered microtubule dynamics in axons and dendrites are major contributors to neurodegenerative diseases such as ALS, Parkinson's disease, Alzheimer's disease, and several tauopathies (59). A recent screen of a $\sim 100$ small molecules identified compounds protective of ER stress in a chemicallyinduced ER stress model of ALS (SOD1 ${ }^{\mathrm{G} 93 \mathrm{~A}}$ ) neurodegeneration (60). Future studies will determine whether compounds that affect microtubule dynamics are able to prevent disease-relevant phenotypes in cellular models of neurodegenerative diseases.

\section{Materials and Methods}

CRISPR/Cas9 Genome Editing of hTERT RPE-1 Cells.

CDG and CDDG lines were generated by CRISPR/Cas9 genome editing of hTERT RPE-1 (ATCC, CRL4000TM) at the Columbia Stem Cell Core Facility. Promoter (U6) and gRNA scaffolds were synthesized by Integrated DNA Technologies (IDT) and cloned into the pCR-Blunt II-TOPO plasmid (ThermoFisher Scientific, cat. K280002). Nucleofector (Lonza) was employed to introduce gRNA and Cas9-GFP plasmids into hTERT RPE-1 cells. After nucleofection, single colonies were manually picked into either 96-well plates or $10 \mathrm{~cm}$ dishes. Cells were incubated for ten days to reach confluency in a 96-well plate or visible colonies in a $10 \mathrm{~cm}$ cell culture dish. For each colony, DNA was extracted by the KAPA Mouse Genotyping Kit (KAPA Biosystems) and genotyped by Sanger sequencing.

Guide RNA scaffold and termination signal:

GTTTTAGAGCTAGAAATAGCAAGTTAAAATAAGGCTAGTCCGTTATCAACTTGAAAAAGTGGCAC CGAGTCGGTGCTTTTTTT gRNA NGLY1: GGTGATTGCCAGAAGAACTAAGG, PMM2: GAATTCAATGAAAGTACCCCTGG, DPAGT1: CATGATCTTCCTGGGCTTTGCGG 


\section{Chemicals.}

Tunicamycin (cat. 3516), salubrinal (cat. 2347), omeprazole (cat. 2583) were purchased from Tocris. Dexlansoprazole (cat. HY-13662B) and rapamycin (cat. HY-10219) were obtained from MedChemExpress. Rabeprazole (cat. 14939) was from Cayman Chemicals. All screened compounds were provided by Janssen Pharmaceuticals. All compounds were suspended in DMSO, aliquoted, and stored at $-20^{\circ} \mathrm{C}$.

\section{Proliferation measurements, MTT assay.}

Cells were seeded in 96-well tissue culture plates $\left(1 \times 10^{3}\right.$ cells per well) and treated the next day as described in 'Results'. At the indicated time points, the medium was removed, and fresh medium containing $0.5 \mathrm{mg} / \mathrm{ml}$ MTT (3-(4,5-dimethylthiazol-2-yl)-2,5-diphenyltetrazolium bromide, Sigma-Aldrich) was added to each well. The cells were incubated at $37^{\circ} \mathrm{C}$ for $4 \mathrm{~h}$ and then an equal volume of solubilization solution $(0.01 \mathrm{~N} \mathrm{HCl}$ in $10 \%$ SDS) was added to each well and mixed thoroughly. The optical density from the plates was read at $570 \mathrm{~nm}$, and background absorbance read at $690 \mathrm{~nm}$. A statistical analysis of the results was performed using the GraphPad Prism software (v.8.2.0). One-way ANOVA multiple comparisons and Dunnett test were used to determine the equality of the means of different samples. The confidence level (p) was 0.05.

\section{Quantitative RT-PCR.}

Total RNA was extracted by RNeasy Plus Mini kit (QIAGEN, cat. 74136). Total RNA (500 ng) was reversetranscribed with random primers using Superscript IV Reverse Transcriptase kit (ThermoFisher Scientific, cat. 18091200). One $\mu \mathrm{L}$ of cDNA was used in each qPCR reaction on a QuantStudio 5 (ThermoFisher Scientific) using SYBR Green PCR Master Mix (ThermoFisher Scientific, cat. 4364344). PCR primers detecting spliced and unspliced $X B P 1$ expression were as described $(61,62)$. Each reaction was performed in duplicate with an initial holding step of $95^{\circ} \mathrm{C}(10 \mathrm{~min})$ followed by 40 cycles of $95^{\circ} \mathrm{C}(10 \mathrm{~s})$ and $55^{\circ} \mathrm{C}(30 \mathrm{~s}) . \mathrm{N}=\geq 3$ for each experiment. The relative expression levels of target genes were normalized to that of the reference GAPDH gene by using the $\Delta \Delta \mathrm{Ct}$ method (63). The fold change in expression for each sample is relative to parental hTERT RPE-1 cells treated with vehicle. Data were graphed using Prism 8 software.

The following sets of primers were used for real-time PCR: for human total XBP1, TGGCCGGGTCTGCTGAGTCCG and ATCCATGGGAAGATGTTCTGG; spliced XBP1, CTGAGTCCGAATCAGGTGCAG and ATCCATGGGAAGATGTTCTGG; for human GAPDH, ACAGTCAGCCGCATCTTCTT and TTGATTTTGGAGGGATCTCG.

\section{Immunoblot analysis.}

Cell lysates were prepared on ice in RIPA buffer (Sigma-Aldrich, cat. R0278) with freshly added cocktail of proteases (Millipore-Sigma, cat. 11836170001) and phosphatases (Millipore Sigma, cat.4906837001) inhibitors. Protein concentrations were determined using Pierce BCA Protein assay kit (ThermoFisher Scientific, cat.23227). Whole cell lysates (20-50 $\mu \mathrm{g})$ were subjected to SDS-PAGE, transferred to PVDF membrane (Immobilon-P, Millipore, cat. IPVH00010), and membranes were blocked and probed by overnight incubation with appropriate primary antibodies. Antibodies: p-eIF2 $\alpha$ (Ser51) and eIF-2 $\alpha$ (Cell Signaling Technology, cat. 9721 and 9722). NGLY1 rabbit polyclonal antibody (Bethyl Laboratories, cat. A305-547A-T), mouse monoclonal ATF6 and mouse monoclonal PMM2 (2E9) (Novus Biologicals, cat. NBP1-40256 and H00005373M01). DPAGT1 rabbit polyclonal antibody (Abcam, cat. ab116667). Bound antibodies were visualized with corresponding HRP-conjugated secondary antibodies (ThermoFisher Scientific, cat. 32260 and 31430) and detected by ECL chemistry (SuperPico West, ThermoFisher Scientific, cat. 34580). Western blots were quantitatively analyzed via laser-scanning densitometry using NIH ImageJ Version $1.52 \mathrm{k}$ software. IB for $\beta$ actin (Santa Cruz, cat. sc-47778) was used to ascertain equal protein loading across samples.

\section{Immunocytochemistry.}

hTERT RPE-1 and the isogenic mutant lines were seeded on poly-D-lysine-coated $12 \mathrm{~mm}$ glass coverslips at a density of $5 \times 10^{4}$ cells/well. Next day, cells were quickly washed with phosphate buffered saline (PBS) and then 
fixed with 4\% paraformaldehyde (PFA) for 10 min at RT. Following three washes in PBS, cells were incubated with permeabilization buffer (1\% Triton X-100 in PBS) for $15 \mathrm{~min}$ at RT, and block in staining buffer $(1 \%$ bovine serum albumin, $0.1 \%$ Triton X-100 in PBS) for 1 hour at RT. Cells were incubated with primary antibodies diluted in staining buffer for 1.5 hours at RT, washed three times with PBS, then incubated with the appropriate fluorescently labeled secondary antibodies diluted in staining solution for 30 min at RT in the dark. Finally, the cells were washed three times with PBS, and coverslips were mounted on microscopy slides using Prolong Antifade DAPI (Invitrogen) and allowed to cure overnight at RT in the dark before imaging. Primary antibodies: mouse monoclonal PMM2 (2E9) (Novus Biologicals, H00005373-M01, 1:500), DPAGT1 rabbit polyclonal antibody (Abcam, cat. ab116667, 1:500), mouse anti-CHOP clone L637F (Cell Signaling Technology, cat. 2895, 1:3200), rabbit anti-GADD153/CHOP (Novus Biologicals, cat. NBP2-58505, 1:500), mouse anti-LAMP-1/CD107a, clone H4A3 (Novus Biologicals, cat. NBP225183, 1:500), mouse antiSQSTM1/p62 (Abcam, cat. ab56416, 1:200), rabbit anti-P4HB/PDIA1 (Abcam, cat. ab3672, 1:200), LC3A (D50G8) XP rabbit monoclonal antibody (Cell Signaling Technology, cat. 4599). Secondary antibodies, donkey anti-mouse or donkey anti-rabbit conjugated to either Alexa Fluor 488 or 568 (Invitrogen, cat. A32766, A32790, A10042, A10037, 1:1000). Imaging was performed on an inverted Zeiss AxioObserver Z1 fluorescent microscope equipped with an AxioCam 503 mono camera and filters for $405 \mathrm{~nm}, 488 \mathrm{~nm}$, and $568 \mathrm{~nm}$. Images were acquired with Zen 2 software and post-processing was performed with Zen 2 and AdobePhotoshop.

Senescence detection, $\beta$-Galactosidase Staining.

Cells were seeded in 6 well plates $\left(1 \times 10^{5} /\right.$ well) overnight, and next day were stained for $\beta$-galactosidase using Senescence $\beta$-Galactosidase Staining Kit (Cell Signaling Technology, cat. 9860) according to manufacturer's instruction. The images were acquired, and the number of stained cells was counted using Zeiss Primovert inverted brightfield and phase contrast microscope equipped with AxioCam ERc5s camera.

Apoptosis detection by Annexin-V binding assay.

Cells were suspended in 1x Annexin V binding buffer (10 mM HEPES/NaOH, pH 7.4, $150 \mathrm{mM} \mathrm{NaCl}, 2.5 \mathrm{mM}$ $\mathrm{CaCl}_{2}$ ) before staining with APC-labeled Annexin-V (BD Biosciences, cat. 550474) according to the manufacturer's instructions. Propidium iodide (PI) was added to the samples after staining with Annexin-V to exclude late apoptotic and necrotic cells. FACS was performed immediately after staining on FACSCelesta (BD Biosystems). Data were analyzed using FlowJo v. 10.5.3 and Prism8 v8.2.0 software.

Autophagy detection using CYTO-ID ${ }^{\circledR}$ Autophagy detection kit (ENZO Life Sciences, cat. ENZ-51031-K200). For fluorescent microscopy, cells were seeded on poly-D-lysine-coated $12 \mathrm{~mm}$ glass coverslips at a density of $5 \times 10^{4}$ cells/well. The next day, cells were washed with PBS, stained with CYTO-ID ${ }^{\circledR}$ Green reagent according to manufacturer's instructions, and observed using an inverted Zeiss AxioObserver Z1 epifluorescent microscope equipped with an AxioCam 503 mono camera. Image post-processing was performed with Zen 2 and Adobe Photoshop software. For flow cytometry analysis, cells were trypsinized, collected by centrifugation, washed with PBS and stained using CYTO-ID ${ }^{\circledR}$ stain solution (ENZO Life Sciences, cat. ENZ51031-K200) according to manufacturer's instructions and immediately analyzed on a FACSCelesta cytometer (BD Biosystems). Data were analyzed using FlowJo v. 10.5.3 and Prism8 v8.2.0 software.

Autophagy detection by p62 and LAMP1 staining. Cells were collected by trypsinization, washed with PBS and fixed with $4 \%$ PFA/PBS for $15 \mathrm{~min}$ at RT. Fixed cells $\left(10^{6}\right.$ cells/sample $)$ were permeabilized using Intracellular Staining Permeabilization Wash buffer (BioLegend, cat.421002) according to the manufacturer instructions and stained with primary mouse monoclonal antibodies for SQSTM1/p62 (Abcam, cat. ab56416, 1:1000), LAMP1/CD107a, clone H4A3 (Novus Biologicals, cat. NBP225183, 1:500), or mouse IgG isotype control antibody (ThermoFisher Scientific, cat. MA5-14453, 1:500) for $1 \mathrm{hr}$ at RT. After two washes with PBS, cells were incubated for $30 \mathrm{~min}$ at RT with Alexa-488 labeled secondary goat anti-mouse antibody (ThermoFisher Scientific, cat. A32723, 1:1000), washed again twice with PBS and analyzed using flow 
cytometry on a FACSCelesta cytometer (BD Biosystems). The data were processed using FlowJo v. 10.5.3 and Prism8 v8.2.0 software.

Cellular morphology assessment by immunostaining. Cells were seeded in 96 well plates at a density of $1 \times 10^{3}$ cells/well, and next day were treated with tested compounds, vehicle (DMSO) or positive controls as described in Materials and Methods. After $24 \mathrm{hrs,} \mathrm{cells} \mathrm{were} \mathrm{washed} \mathrm{with} \mathrm{PBS,} \mathrm{fixed} \mathrm{with} \mathrm{4 \%} \mathrm{PFA/PBS} \mathrm{for} 15$ min at RT, blocked with 1\% BSA/PBS for 30 min and stained with Alexa 568 labeled phalloidin (ThermoFisher Scientific, cat. A12380) for 30 min. After two washes with PBS, cells were stained with 300nM DAPI (BD Pharmingen, cat. 564907). Imaging was performed with an inverted Zeiss AxioObserver Z1 epifluorescent microscope equipped with an AxioCam 503 mono camera, and images acquired with the Zen 2 software. Postprocessing was performed with Zen 2 and AdobePhotoshop software.

\section{High-content imaging and compound screening}

The hTERT RPE-1 cells and $N G L Y 1^{-/}, P M M 2^{F 119 L /-}$, and DPAGT1 ${ }^{+/-}$mutant lines were plated in 384 well plates at a density of 3,000 cells per well. The next day compounds were added to the cells at a final concentration of $10 \mu \mathrm{M}$ and incubated for 24 hours. MitoTracker Red (Molecular Probes, cat. M7512) mitochondrial stain was added to the media, following the manufacturer's protocol. After 30 minutes of labeling, media was removed, cells were fixed in 4\% PFA in PBS, washed, permeabilized with $0.1 \%$ NP-40, and blocked with 3\% BSA in PBS overnight. For staining, ConcanavalinA-488 (Molecular Probes, cat. C11252), phalloidin-547 (Molecular Probes, cat. A22283), and DAPI were added to the wells, then washed before imaging. Images were acquired on a Molecular Devices Image Express microscope at 4 fields per well. Feature extraction from images was done with Perkin-Elmer Columbus Image Analysis software, and feature analysis and hit determination was performed using TIBCO Spotfire analysis package.

\section{Secondary validation of selected compounds.}

Candidate and control compounds from the high-throughput screen were validated in using two assays, MTT to assess proliferation and RT-qPCR for $\mathrm{s} X B P 1$ expression as described above. Parental hTERT RPE-1 cells and their edited clones were seeded in 6-well $\left(10^{5}\right.$ cells/well, for RNA assay) or 96 -well ( $10^{3}$ cells/well, for MTT assay) plates and in a humidified incubator at $37^{\circ} \mathrm{C}$ and $5 \% \mathrm{CO}_{2}$, and treated with candidate or control compounds. Dose response curves on hTERT RPE-1 cells identified the lowest non-toxic concentration for each of the candidate compounds. Cells were treated for $24 \mathrm{~h}$ with Group I (5.0 nM), Group II (1.0 nM), or non-active control $(10 \mu \mathrm{M})$ compounds. Concentrations of PPI were; DxP $50 \mu \mathrm{M}$, OmP and RbP $100 \mu \mathrm{M}$. Post treatment, total RNA was collected in RLT buffer (QIAGEN) containing $\beta$-mercaptoethanol for RT-qPCR. Alternatively, cells were subjected to MTT assay at days $0,1,3$ and 5 post-treatment.

\section{Statistical analyses}

Results are expressed as mean \pm SEM for a minimum of 3 independent experiments. Sample size and statistical tests are detailed in the figure legends. Statistical analysis was performed using one-way ANOVA followed by Dunnett multiple comparisons post-test to compare each condition to vehicle-treated controls. $\mathrm{P}$ values $\leq .05$ were considered significant.

Acknowledgments. We thank Guy Ludwig and other past and present members of the Institute for Genomic Medicine for insights and helpful discussions.

Author contributions (according to CRediT, https://www.casrai.org/credit.html)

Conceptualization: D.B.G., M.J.B., Y-F.L., M.V.W., J.W.

Data Curation: I.V.L., M.V.W., S.S.

Formal Analysis: I.V.L., M.V.W., S.S. 
Investigation: I.V.L., M.V.W., S.S.

Methodology: I.V.L., M.V.W., Y-F.L.

Project Administration: I.V.L., M.V.W., A.A-O., J.W., M.J.B.

Resources:

Software:

Supervision: M.J.B., J.W., D.B.G.

Validation: I.V.L., M.V.W., S.S., M.J.B.

Visualization: I.V.L., M.J.B.

Writing - Original Draft: I.V.L., M.J.B., D.B.G.

Writing - Review \& Editing: I.V.L., M.V.W., M.B.H., M.J.B., D.B.G.

\section{Competing interests}

D.B.G. is a founder of and holds equity in Praxis, serves as a consultant to AstraZeneca, and has received research support from Janssen, Gilead, Biogen, AstraZeneca and UCB. M.B.H. serves as a consultant to the Muscular Dystrophy Association, and receives research support from Biogen. All other authors declare no competing interests. 


\section{References}

1. B. D. Roussel, A. J. Kruppa, E. Miranda, D. C. Crowther, D. A. Lomas, S. J. Marciniak, Endoplasmic reticulum dysfunction in neurological disease. Lancet Neurol 12, 105-118 (2013).

2. J. Jung, M. Michalak, L. B. Agellon, Endoplasmic Reticulum Malfunction in the Nervous System. Front Neurosci 11, 220 (2017).

3. C. Hetz, S. Saxena, ER stress and the unfolded protein response in neurodegeneration. Nat Rev Neurol 13, $477-$ 491 (2017).

4. J. Jaeken, Congenital disorders of glycosylation. Ann N Y Acad Sci 1214, 190-198 (2010).

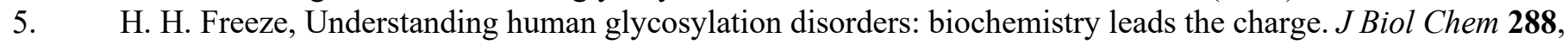
6936-6945 (2013).

6. G. M. Enns, V. Shashi, M. Bainbridge, M. J. Gambello, F. R. Zahir, T. Bast, R. Crimian, K. Schoch, J. Platt, R. Cox, J. A. Bernstein, M. Scavina, R. S. Walter, A. Bibb, M. Jones, M. Hegde, B. H. Graham, A. C. Need, A. Oviedo, C. P. Schaaf, S. Boyle, A. J. Butte, R. Chen, R. Chen, M. J. Clark, R. Haraksingh, T. M. Cowan, P. He, S. Langlois, H. Y. Zoghbi, M. Snyder, R. A. Gibbs, H. H. Freeze, D. B. Goldstein, Mutations in NGLY1 cause an inherited disorder of the endoplasmic reticulum-associated degradation pathway. Genet Med 16, 751-758 (2014).

7. G. Matthijs, E. Schollen, E. Pardon, M. Veiga-Da-Cunha, J. Jaeken, J. J. Cassiman, E. Van Schaftingen, Mutations in PMM2, a phosphomannomutase gene on chromosome 16p13, in carbohydrate-deficient glycoprotein type I syndrome (Jaeken syndrome). Nat Genet 16, 88-92 (1997).

8. L. Sun, Y. Zhao, K. Zhou, H. H. Freeze, Y. W. Zhang, H. Xu, Insufficient ER-stress response causes selective mouse cerebellar granule cell degeneration resembling that seen in congenital disorders of glycosylation. $\mathrm{Mol}$ Brain 6, 52 (2013).

9. A. Heifetz, R. W. Keenan, A. D. Elbein, Mechanism of action of tunicamycin on the UDP-GlcNAc:dolichylphosphate Glc-NAc-1-phosphate transferase. Biochemistry 18, 2186-2192 (1979).

10. X. Wu, J. S. Rush, D. Karaoglu, D. Krasnewich, M. S. Lubinsky, C. J. Waechter, R. Gilmore, H. H. Freeze, Deficiency of UDP-GlcNAc:Dolichol Phosphate N-Acetylglucosamine-1 Phosphate Transferase (DPAGT1) causes a novel congenital disorder of Glycosylation Type Ij. Hum Mutat 22, 144-150 (2003).

11. A. E. Wurde, J. Reunert, S. Rust, C. Hertzberg, S. Haverkamper, G. Nurnberg, P. Nurnberg, L. Lehle, R. Rossi, T. Marquardt, Congenital disorder of glycosylation type Ij (CDG-Ij, DPAGT1-CDG): extending the clinical and molecular spectrum of a rare disease. Mol Genet Metab 105, 634-641 (2012).

12. E. Van Schaftingen, J. Jaeken, Phosphomannomutase deficiency is a cause of carbohydrate-deficient glycoprotein syndrome type I. FEBS Lett 377, 318-320 (1995).

13. J. M. van de Kamp, D. J. Lefeber, G. J. Ruijter, S. J. Steggerda, N. S. den Hollander, S. M. Willems, G. Matthijs, B. J. Poorthuis, R. A. Wevers, Congenital disorder of glycosylation type Ia presenting with hydrops fetalis. J Med Genet 44, 277-280 (2007).

14. S. Kjaergaard, M. Schwartz, F. Skovby, Congenital disorder of glycosylation type Ia (CDG-Ia): phenotypic spectrum of the R141H/F119L genotype. Archives of Disease in Childhood 85, 236-239 (2001).

15. P. J. Thul, L. Åkesson, M. Wiking, D. Mahdessian, A. Geladaki, H. Ait Blal, T. Alm, A. Asplund, L. Björk, L. M. Breckels, A. Bäckström, F. Danielsson, L. Fagerberg, J. Fall, L. Gatto, C. Gnann, S. Hober, M. Hjelmare, F. Johansson, S. Lee, C. Lindskog, J. Mulder, C. M. Mulvey, P. Nilsson, P. Oksvold, J. Rockberg, R. Schutten, J. M. Schwenk, Å. Sivertsson, E. Sjöstedt, M. Skogs, C. Stadler, D. P. Sullivan, H. Tegel, C. Winsnes, C. Zhang, M. Zwahlen, A. Mardinoglu, F. Pontén, K. von Feilitzen, K. S. Lilley, M. Uhlén, E. Lundberg, A subcellular map of the human proteome. Science 356, eaal3321 (2017).

16. M. Uhlén, L. Fagerberg, B. M. Hallström, C. Lindskog, P. Oksvold, A. Mardinoglu, Å. Sivertsson, C. Kampf, E. Sjöstedt, A. Asplund, I. Olsson, K. Edlund, E. Lundberg, S. Navani, C. A.-K. Szigyarto, J. Odeberg, D. Djureinovic, J. O. Takanen, S. Hober, T. Alm, P.-H. Edqvist, H. Berling, H. Tegel, J. Mulder, J. Rockberg, P. Nilsson, J. M. Schwenk, M. Hamsten, K. von Feilitzen, M. Forsberg, L. Persson, F. Johansson, M. Zwahlen, G. von Heijne, J. Nielsen, F. Pontén, Tissue-based map of the human proteome. Science 347, 1260419 (2015).

17. M. R. Lecca, U. Wagner, A. Patrignani, E. G. Berger, T. Hennet, Genome-wide analysis of the unfolded protein response in fibroblasts from congenital disorders of glycosylation type-I patients. FASEB journal : official publication of the Federation of American Societies for Experimental Biology 19, 240-242 (2005).

18. V. Coppola-Segovia, C. Cavarsan, F. G. Maia, A. C. Ferraz, L. S. Nakao, M. M. Lima, S. M. Zanata, ER Stress Induced by Tunicamycin Triggers alpha-Synuclein Oligomerization, Dopaminergic Neurons Death and Locomotor Impairment: a New Model of Parkinson's Disease. Mol Neurobiol 54, 5798-5806 (2017). 
19. J. Shang, Quantitative measurement of events in the mammalian unfolded protein response. Methods Enzymol 491, 293-308 (2011).

20. M. Boyce, K. F. Bryant, C. Jousse, K. Long, H. P. Harding, D. Scheuner, R. J. Kaufman, D. Ma, D. M. Coen, D. Ron, J. Yuan, A selective inhibitor of eIF2alpha dephosphorylation protects cells from ER stress. Science 307, 935-939 (2005).

21. J. Celli, R. M. Tsolis, Bacteria, the endoplasmic reticulum and the unfolded protein response: friends or foes? Nat Rev Microbiol 13, 71-82 (2015).

22. H.-O. Rashid, R. K. Yadav, H.-R. Kim, H.-J. Chae, ER stress: Autophagy induction, inhibition and selection. Autophagy 11, 1956-1977 (2015).

23. L. L. Chan, D. Shen, A. R. Wilkinson, W. Patton, N. Lai, E. Chan, D. Kuksin, B. Lin, J. Qiu, A novel imagebased cytometry method for autophagy detection in living cells. Autophagy 8, 1371-1382 (2012).

24. A. E. Carpenter, T. R. Jones, M. R. Lamprecht, C. Clarke, I. H. Kang, O. Friman, D. A. Guertin, J. H. Chang, R. A. Lindquist, J. Moffat, P. Golland, D. M. Sabatini, CellProfiler: image analysis software for identifying and quantifying cell phenotypes. Genome Biol 7, R100 (2006).

25. S. M. Gustafsdottir, V. Ljosa, K. L. Sokolnicki, J. Anthony Wilson, D. Walpita, M. M. Kemp, K. Petri Seiler, H. A. Carrel, T. R. Golub, S. L. Schreiber, P. A. Clemons, A. E. Carpenter, A. F. Shamji, Multiplex Cytological Profiling Assay to Measure Diverse Cellular States. PLOS ONE 8, e80999 (2013).

26. Y. Bi, M. Might, H. Vankayalapati, B. Kuberan, Repurposing of Proton Pump Inhibitors as first identified small molecule inhibitors of endo-beta-N-acetylglucosaminidase (ENGase) for the treatment of NGLY1 deficiency, a rare genetic disease. Bioorganic \& medicinal chemistry letters 27, 2962-2966 (2017).

27. A. M. Brum, J. van de Peppel, C. S. van der Leije, M. Schreuders-Koedam, M. Eijken, B. C. van der Eerden, J. P. van Leeuwen, Connectivity Map-based discovery of parbendazole reveals targetable human osteogenic pathway. Proc Natl Acad Sci U S A 112, 12711-12716 (2015).

28. J. Chen, W. L. Sun, B. Wasylyk, Y. P. Wang, H. Zheng, c-Jun N-terminal kinase mediates microtubuledepolymerizing agent-induced microtubule depolymerization and G2/M arrest in MCF-7 breast cancer cells. Anticancer Drugs 23, 98-107 (2012).

29. A. Ganguly, H. Zhang, R. Sharma, S. Parsons, K. D. Patel, Isolation of human umbilical vein endothelial cells and their use in the study of neutrophil transmigration under flow conditions. J Vis Exp, e4032 (2012).

30. L. Gu, P. Talati, P. Vogiatzi, A. L. Romero-Weaver, J. Abdulghani, Z. Liao, B. Leiby, D. T. Hoang, T. Mirtti, K. Alanen, M. Zinda, D. Huszar, M. T. Nevalainen, Pharmacologic suppression of JAK1/2 by JAK1/2 inhibitor AZD1480 potently inhibits IL-6-induced experimental prostate cancer metastases formation. Mol Cancer Ther 13, 1246-1258 (2014).

31. M. A. Jordan, Mechanism of action of antitumor drugs that interact with microtubules and tubulin. Curr Med Chem Anticancer Agents 2, 1-17 (2002).

32. M. A. Jordan, D. Thrower, L. Wilson, Effects of vinblastine, podophyllotoxin and nocodazole on mitotic spindles. Implications for the role of microtubule dynamics in mitosis. J Cell Sci 102 ( Pt 3), 401-416 (1992).

33. S. Kadir, J. W. Astin, L. Tahtamouni, P. Martin, C. D. Nobes, Microtubule remodelling is required for the frontrear polarity switch during contact inhibition of locomotion. J Cell Sci 124, 2642-2653 (2011).

34. H. Minegishi, Y. Futamura, S. Fukashiro, M. Muroi, M. Kawatani, H. Osada, H. Nakamura, Methyl 3-((6methoxy-1,4-dihydroindeno[1,2-c]pyrazol-3-yl)amino)benzoate (GN39482) as a tubulin polymerization inhibitor identified by MorphoBase and ChemProteoBase profiling methods. J Med Chem 58, 4230-4241 (2015).

35. K. Oukoloff, J. Kovalevich, A. S. Cornec, Y. Yao, Z. A. Owyang, M. James, J. Q. Trojanowski, V. M. Lee, A. B. Smith, 3rd, K. R. Brunden, C. Ballatore, Design, synthesis and evaluation of photoactivatable derivatives of microtubule (MT)-active [1,2,4]triazolo[1,5-a]pyrimidines. Bioorg Med Chem Lett 28, 2180-2183 (2018).

36. M. W. Rochlin, K. M. Wickline, P. C. Bridgman, Microtubule stability decreases axon elongation but not axoplasm production. J Neurosci 16, 3236-3246 (1996).

37. Z. Sahenk, S. T. Brady, Axonal tubulin and microtubules: morphologic evidence for stable regions on axonal microtubules. Cell Motil Cytoskeleton 8, 155-164 (1987).

38. V. Sengottuvel, D. Fischer, Facilitating axon regeneration in the injured CNS by microtubules stabilization. Commun Integr Biol 4, 391-393 (2011).

39. D. V. Tsyganov, V. N. Khrustalev, L. D. Konyushkin, M. M. Raihstat, S. I. Firgang, R. V. Semenov, A. S. Kiselyov, M. N. Semenova, V. V. Semenov, 3-(5-)-Amino-o-diarylisoxazoles: regioselective synthesis and antitubulin activity. Eur J Med Chem 73, 112-125 (2014). 
40. D. V. Tsyganov, L. D. Konyushkin, I. B. Karmanova, S. I. Firgang, Y. A. Strelenko, M. N. Semenova, A. S. Kiselyov, V. V. Semenov, cis-Restricted 3-aminopyrazole analogues of combretastatins: synthesis from plant polyalkoxybenzenes and biological evaluation in the cytotoxicity and phenotypic sea urchin embryo assays. $J$ Nat Prod 76, 1485-1491 (2013).

41. P. S. Gurel, A. L. Hatch, H. N. Higgs, Connecting the cytoskeleton to the endoplasmic reticulum and Golgi. Curr Biol 24, R660-R672 (2014).

42. Q. A. Sun, D. T. Hess, B. Wang, M. Miyagi, J. S. Stamler, Off-target thiol alkylation by the NADPH oxidase inhibitor 3-benzyl-7-(2-benzoxazolyl)thio-1,2,3-triazolo[4,5-d]pyrimidine (VAS2870). Free Radic Biol Med 52, 1897-1902 (2012).

43. K. Bala Bhaskara Rao, K. Katragunta, U. M. Sarma, N. Jain, Abundance of d-2-hydroxyglutarate in G2/M is determined by FOXM1 in mutant IDH1-expressing cells. FEBS Lett 593, 2177-2193 (2019).

44. S. Ioannidis, M. L. Lamb, T. Wang, L. Almeida, M. H. Block, A. M. Davies, B. Peng, M. Su, H. J. Zhang, E. Hoffmann, C. Rivard, I. Green, T. Howard, H. Pollard, J. Read, M. Alimzhanov, G. Bebernitz, K. Bell, M. Ye, D. Huszar, M. Zinda, Discovery of 5-chloro-N2-[(1S)-1-(5-fluoropyrimidin-2-yl)ethyl]-N4-(5-methyl-1H-pyrazol-3yl)p yrimidine-2,4-diamine (AZD1480) as a novel inhibitor of the Jak/Stat pathway. J Med Chem 54, 262-276 (2011).

45. L. T. Alexander, H. Mobitz, P. Drueckes, P. Savitsky, O. Fedorov, J. M. Elkins, C. M. Deane, S. W. CowanJacob, S. Knapp, Type II Inhibitors Targeting CDK2. ACS Chem Biol 10, 2116-2125 (2015).

46. C. R. Coxon, E. Anscombe, S. J. Harnor, M. P. Martin, B. Carbain, B. T. Golding, I. R. Hardcastle, L. K. Harlow, S. Korolchuk, C. J. Matheson, D. R. Newell, M. E. Noble, M. Sivaprakasam, S. J. Tudhope, D. M. Turner, L. Z. Wang, S. R. Wedge, C. Wong, R. J. Griffin, J. A. Endicott, C. Cano, Cyclin-Dependent Kinase (CDK) Inhibitors: Structure-Activity Relationships and Insights into the CDK-2 Selectivity of 6-Substituted 2-Arylaminopurines. $J$ Med Chem 60, 1746-1767 (2017).

47. F. Marchetti, C. Cano, N. J. Curtin, B. T. Golding, R. J. Griffin, K. Haggerty, D. R. Newell, R. J. Parsons, S. L. Payne, L. Z. Wang, I. R. Hardcastle, Synthesis and biological evaluation of 5-substituted O4-alkylpyrimidines as CDK2 inhibitors. Org Biomol Chem 8, 2397-2407 (2010).

48. T. K. Nguyen, S. Grant, Dinaciclib (SCH727965) inhibits the unfolded protein response through a CDK1- and 5dependent mechanism. Mol Cancer Ther 13, 662-674 (2014).

49. M. Hedvat, D. Huszar, A. Herrmann, J. M. Gozgit, A. Schroeder, A. Sheehy, R. Buettner, D. Proia, C. M. Kowolik, H. Xin, B. Armstrong, G. Bebernitz, S. Weng, L. Wang, M. Ye, K. McEachern, H. Chen, D. Morosini, K. Bell, M. Alimzhanov, S. Ioannidis, P. McCoon, Z. A. Cao, H. Yu, R. Jove, M. Zinda, The JAK2 inhibitor AZD1480 potently blocks Stat3 signaling and oncogenesis in solid tumors. Cancer Cell 16, 487-497 (2009).

50. G. P. Meares, Y. Liu, R. Rajbhandari, H. Qin, S. E. Nozell, J. A. Mobley, J. A. Corbett, E. N. Benveniste, PERKdependent activation of JAK1 and STAT3 contributes to endoplasmic reticulum stress-induced inflammation. Mol Cell Biol 34, 3911-3925 (2014).

51. H. Qin, J. A. Buckley, X. Li, Y. Liu, T. H. Fox, 3rd, G. P. Meares, H. Yu, Z. Yan, A. S. Harms, Y. Li, D. G. Standaert, E. N. Benveniste, Inhibition of the JAK/STAT Pathway Protects Against alpha-Synuclein-Induced Neuroinflammation and Dopaminergic Neurodegeneration. J Neurosci 36, 5144-5159 (2016).

52. L. Lough, D. Sherman, M. Beccera-Flores, O. Lavinda, E. Ni, H. Wang, R. Tibes, T. Cardozo, Triazolo[4,5d]pyrimidines as Validated General Control Nonderepressible 2 (GCN2) Protein Kinase Inhibitors Reduce Growth of Leukemia Cells. Comput Struct Biotechnol J 16, 350-360 (2018).

53. D. Dorsch, G. Hoelzemann, K. Schiemann, A. Wegener, Triazolo[4,5-d]pyrimidine derivatives. Merck Patent GmbH. US Patent \& Trademark Office Patent Full Text and Image Database, Pat. 9,409,914 (2016).

54. C. Y. Ho, B. A. Brunmark, S. Emanuel, J. Galemmo, Robert A, D. L. Johnson, D. W. Ludovichi, U. Maharoof, J. M. Mei, J. L. Sechler, E. D. Strobel, R. W. Tuman, H. K. Yen, N-substituted tricyclic 3-aminopyrazoles as inhibitors for the treatment of cell proliferative disorders. Janssen Parmaceutica N.V. (BE). US Patent \& Trademark Office Patent Full Text and Image Database, Pat. 7,196,110 (2007).

55. E. Menu, H. Jernberg-Wiklund, H. De Raeve, E. De Leenheer, L. Coulton, O. Gallagher, E. Van Valckenborgh, O. Larsson, M. Axelson, K. Nilsson, B. Van Camp, P. Croucher, K. Vanderkerken, Targeting the IGF-1R using picropodophyllin in the therapeutical 5T2MM mouse model of multiple myeloma: beneficial effects on tumor growth, angiogenesis, bone disease and survival. Int J Cancer 121, 1857-1861 (2007).

56. L. Rosengren, D. Vasilcanu, R. Vasilcanu, S. Fickenscher, B. Sehat, N. Natalishvili, S. Naughton, S. Yin, A. Girnita, L. Girnita, M. Axelson, O. Larsson, IGF-1R tyrosine kinase expression and dependency in clones of IGF1R knockout cells (R-). Biochem Biophys Res Commun 347, 1059-1066 (2006). 
57. I. Gudernova, L. Balek, M. Varecha, J. F. Kucerova, M. Kunova Bosakova, B. Fafilek, V. Palusova, S. Uldrijan, L. Trantirek, P. Krejci, Inhibitor repurposing reveals ALK, LTK, FGFR, RET and TRK kinases as the targets of AZD1480. Oncotarget 8, 109319-109331 (2017).

58. T. Marquardt, J. Denecke, Congenital disorders of glycosylation: review of their molecular bases, clinical presentations and specific therapies. European Journal of Pediatrics 162, 359-379 (2003).

59. A. J. Matamoros, P. W. Baas, Microtubules in health and degenerative disease of the nervous system. Brain Res Bull 126, 217-225 (2016).

60. S. Thams, E. R. Lowry, M.-H. Larraufie, K. J. Spiller, H. Li, D. J. Williams, P. Hoang, E. Jiang, L. A. Williams, J. Sandoe, K. Eggan, I. Lieberam, K. C. Kanning, B. R. Stockwell, C. E. Henderson, H. Wichterle, A Stem CellBased Screening Platform Identifies Compounds that Desensitize Motor Neurons to Endoplasmic Reticulum Stress. Molecular Therapy 27, 87-101 (2019).

61. S. G. Fonseca, S. Ishigaki, C. M. Oslowski, S. Lu, K. L. Lipson, R. Ghosh, E. Hayashi, H. Ishihara, Y. Oka, M. A. Permutt, F. Urano, Wolfram syndrome 1 gene negatively regulates ER stress signaling in rodent and human cells. J Clin Invest 120, 744-755 (2010).

62. S. Ishigaki, S. G. Fonseca, C. M. Oslowski, A. Jurczyk, J. R. Shearstone, L. J. Zhu, M. A. Permutt, D. L. Greiner, R. Bortell, F. Urano, AATF mediates an antiapoptotic effect of the unfolded protein response through transcriptional regulation of AKT1. Cell Death Differ 17, 774-786 (2010).

63. K. J. Livak, T. D. Schmittgen, Analysis of relative gene expression data using real-time quantitative PCR and the 2(-Delta Delta C(T)) Method. Methods 25, 402-408 (2001). 
Figure 1
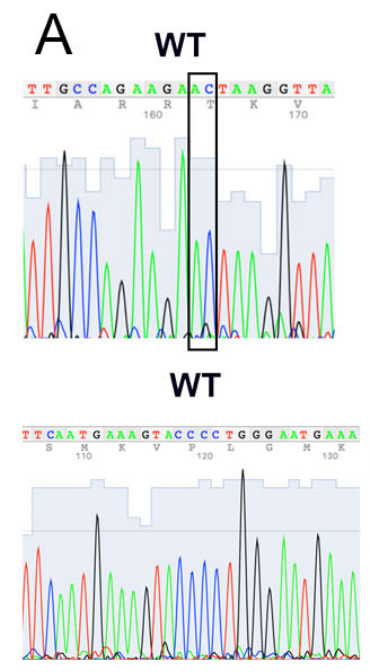

WT

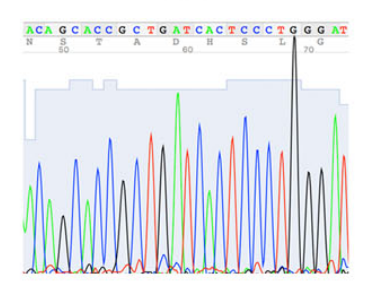

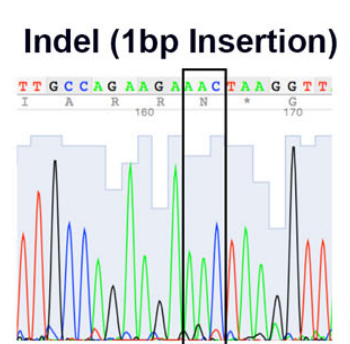

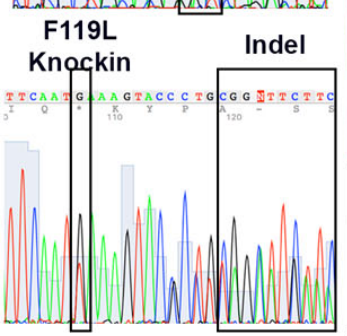

$1 \mathrm{bp}$ Insertion

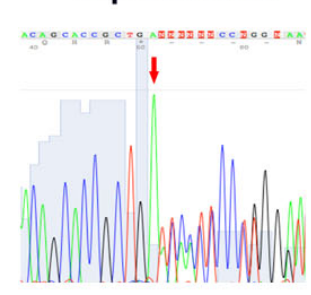

B
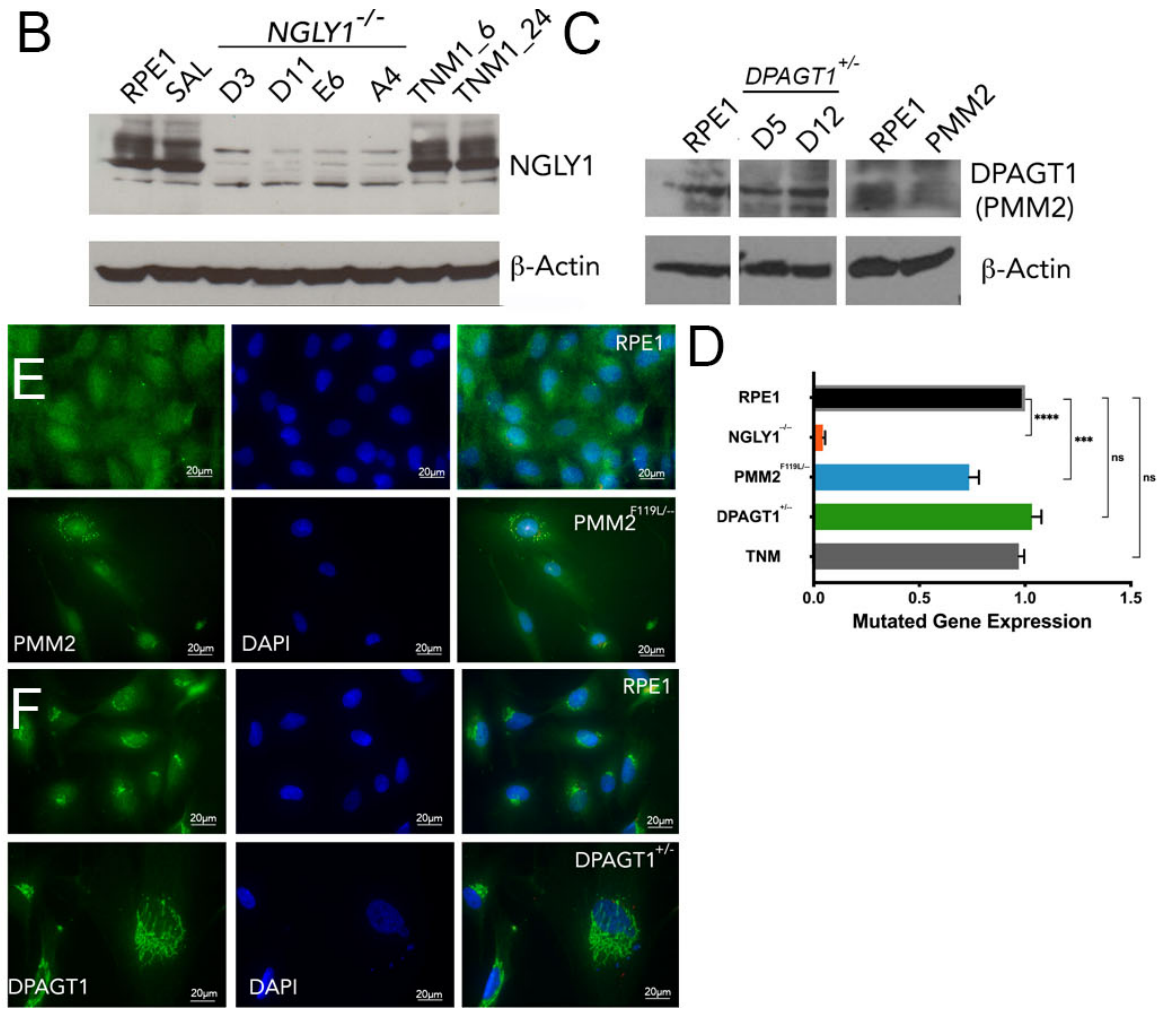

Figure 1. CDG and CDDG cellular models were validated by Sanger sequencing, immunoblot and immunofluorescence staining for target proteins.

A, Electropherogram traces for parental RPE-1 cells, CDDG - NGLY1/- D11 (top), and CDG - PMM2 F119L/- A3 (middle) and $D P A G T 1^{+/-} \mathrm{D} 5$ (bottom) lines. B and C, Immunoblot images for target proteins in RPE-1 and isogenic CDDG (B) and CDG (C) lines. RPE-1 cells treated with TNM ( $1 \mu \mathrm{M}$ for either $6 \mathrm{~h}$ or $24 \mathrm{~h})$ were used as a positive control. D, Quantification of the target protein levels in the edited RPE-1 cells. Expression relative to levels in parental RPE-1 cells. ***, $\mathrm{P}<0.001$, ****, $\mathrm{P}<0.0001$. E and $\mathrm{F}$, Representative immunofluorescence images for staining for PMM2 and DPAGT1 in parental RPE-1, CDG - PMM2 F119L/- A3, and CDG DPAGT1 $1^{+/-}$D5 lines 
Figure 2

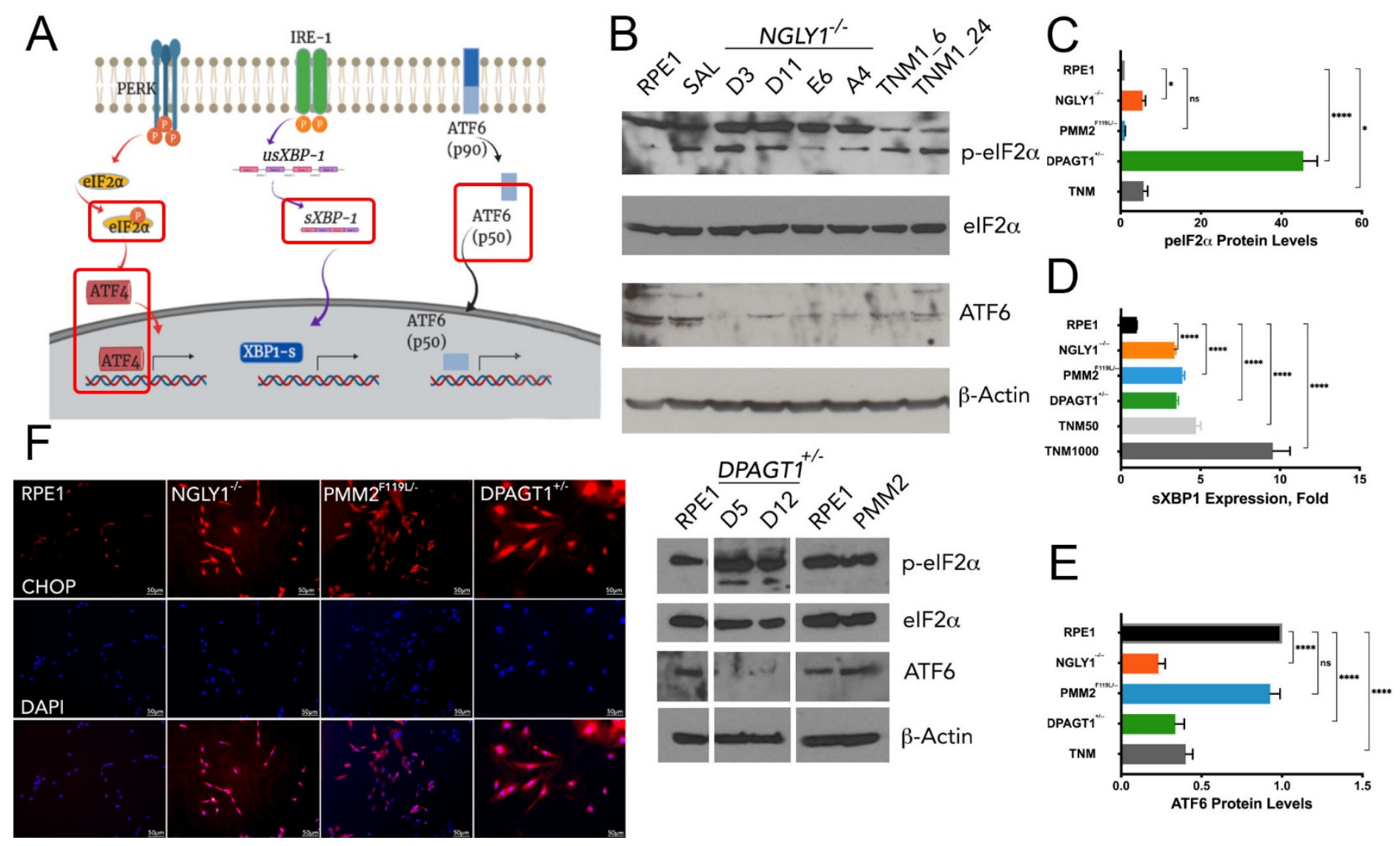

Figure 2. Cellular models of CDG and CDDG exhibit elevated ER stress responses.

A, Schematic of the three major ER stress pathways (analyzed markers are framed). B, Immunoblot images for ER stress markers in RPE-1 and different clones of isogenic CDDG (top) and CDG (bottom) lines. RPE-1 cells treated with TNM $(1 \mu \mathrm{M}$ for either $6 \mathrm{~h}$ or $24 \mathrm{~h})$ and salubrinal (SAL, $50 \mu \mathrm{M}$ for $24 \mathrm{~h})$ were used as negative and positive controls, respectively. C, Quantification of peIF $2 \alpha$ levels relative to total eIF2 $\alpha$ protein. D, Expression of spliced XBP1 transcript. E, Quantification of ATF6 levels in parental and edited RPE-1 cells. Expression data in $\mathrm{C}-\mathrm{E}$ are relative to levels in parental RPE-1 cells. ${ }^{*}, \mathrm{P}<0.05, * *, \mathrm{P}<0.01, * * *, \mathrm{P}<0.001, * * * *$, $\mathrm{P}<0.0001$. F, Nuclear localization of CHOP/ATF4 in parental and edited RPE-1 cells (scale bars are $50 \mu \mathrm{m}$ ). 
Figure 3
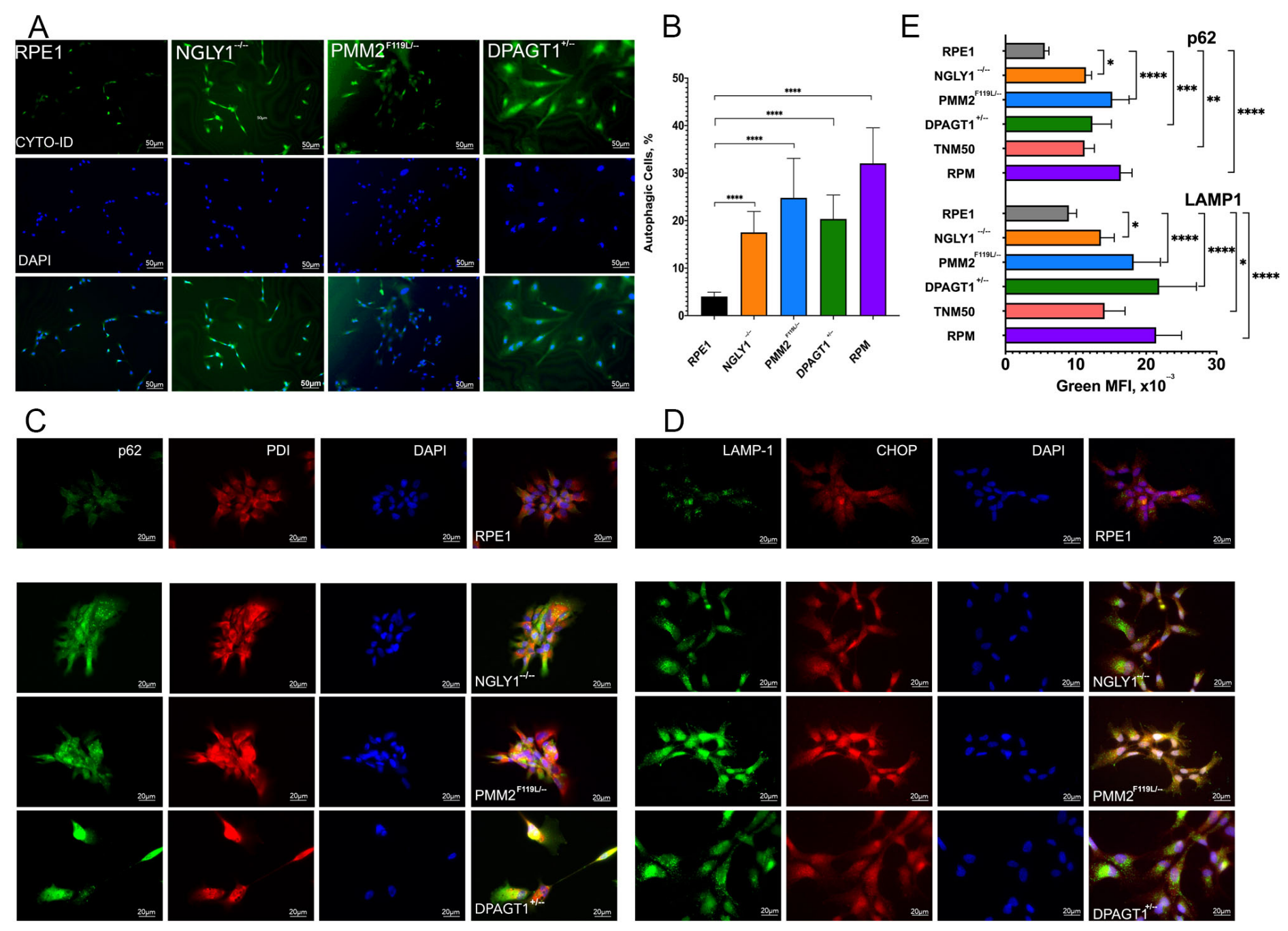

Figure 3. CDG and CDDG lines exhibit elevated autophagy levels.

Cells were stained using CYTO-ID Autophagy Detection Kit and observed by (A) fluorescent microscopy; scale bar, $50 \mu \mathrm{m}$, and (B) analyzed by flow cytometry. C and D, Representative immunofluorescence images of parental RPE-1 cells and CDDG and CDG cell lines stained with antibodies against (C) p62/SQSTM1 or (D) LAMP1 in combination with anti-CHOP or anti-PDI antibodies, respectively. Scale bar, $20 \mu \mathrm{m}$. E, Quantification of p62/SQSTM1 and LAMP1 staining by flow cytometry. *, $\mathrm{P}<0.05, * *, \mathrm{P}<0.01, * * *, \mathrm{P}<0.001$, $* * * *, \mathrm{P}<0.0001$. 


\section{Figure 4}
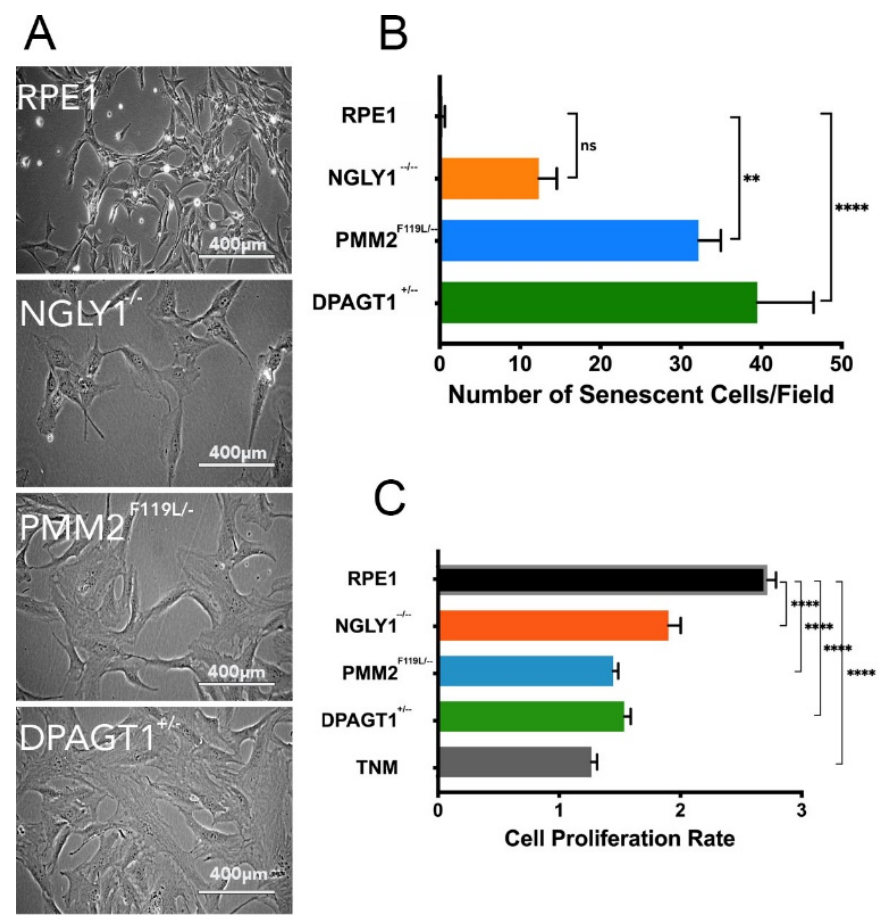

Figure 4. CDG and CDDG lines exhibit line-dependent levels of senescence and reduced proliferation. Isogenic RPE-1 and edited cell lines were seeded in tissue culture plates, cultured for several days, and phase contrast images were taken. Separate set of samples were fixed and stained for $\beta$-Galactosidase, an indicator of senescence. For proliferation assay, cells were seeded in triplicates in 96 well plates, stained every other day with MTT and $\mathrm{OD}_{590}$ was measured. A, Representative phase contrast images of cellular morphology. Scale bars, $400 \mu \mathrm{m}$. B, Quantification of senescence levels as indicated by $\beta$-galactosidase staining. C, Quantification of cellular proliferation rates for CDG and CDDG lines relative to parental RPE-1. To define cell proliferation rate, ratio of $\mathrm{OD}_{590}$ at $72 \mathrm{~h}$ to $\mathrm{OD}_{590}$ at $24 \mathrm{~h}$ post seeding was calculated. $*, \mathrm{P}<0.05, * *$, $\mathrm{P}<0,01, * * * *, \mathrm{P}<0.0001$ 


\section{Figure 5}

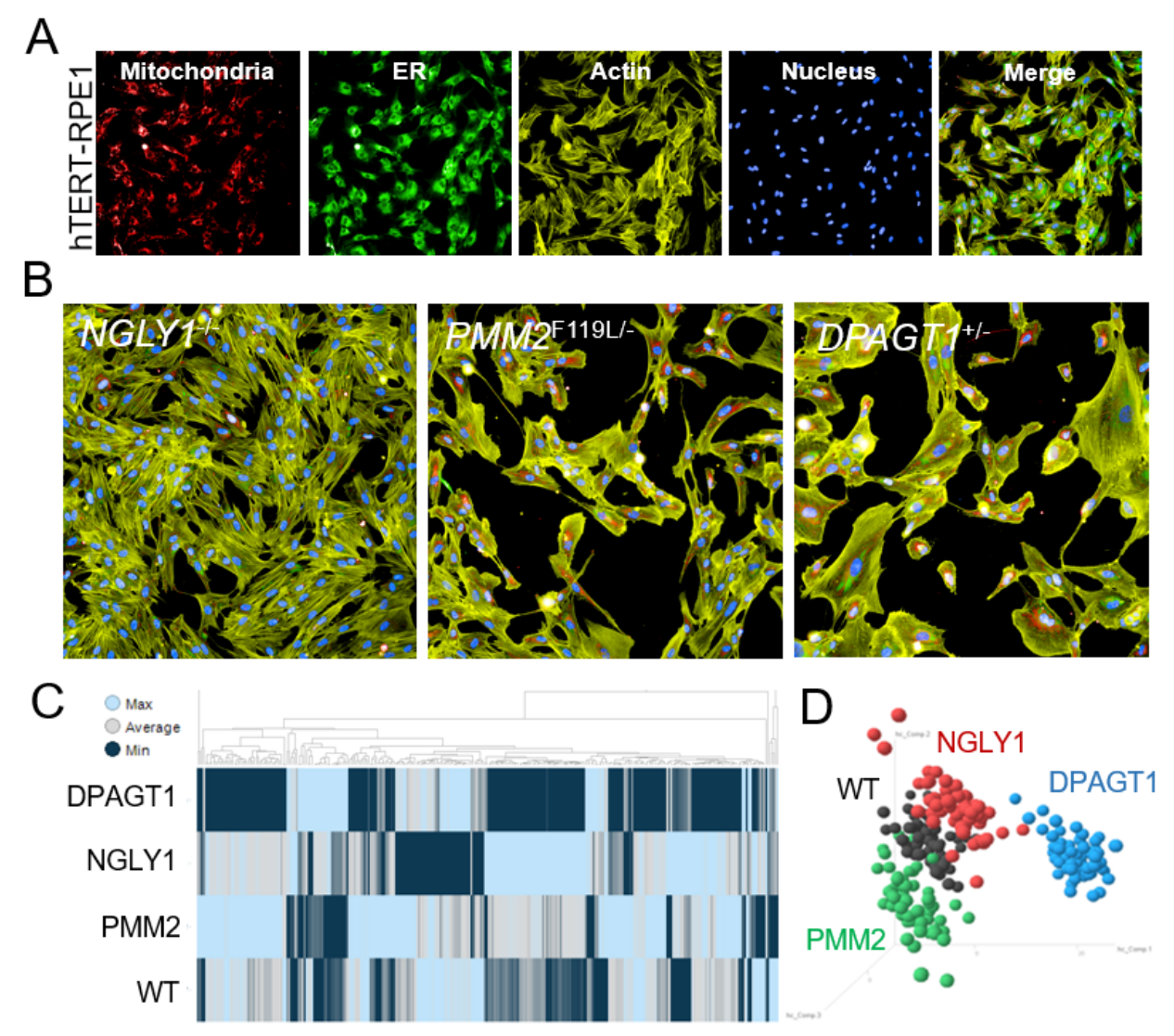

Figure 5. Cell painting assay developed for high-throughput cellular morphology screening identifies line-specific morphological characteristics.

A, Cell painting images of parental RPE-1 cells. Cells were plated in 384-well tissue culture plate and stained with MitoTracker Red (mitochondrial stain), ConcanavalinA-488 (ER stain), phalloidin-547 (actin stain), and DAPI (nuclei) as described in the Methods section. B, Representative cell painting images of CDDG and CDG lines. $\mathrm{C}$ and $\mathrm{D}$, Hierarchical clustering and principal component analyses of extracted morphological features distinguishes CDG and CDDG cell lines from parental RPE-1 cells 


\section{Figure 6}

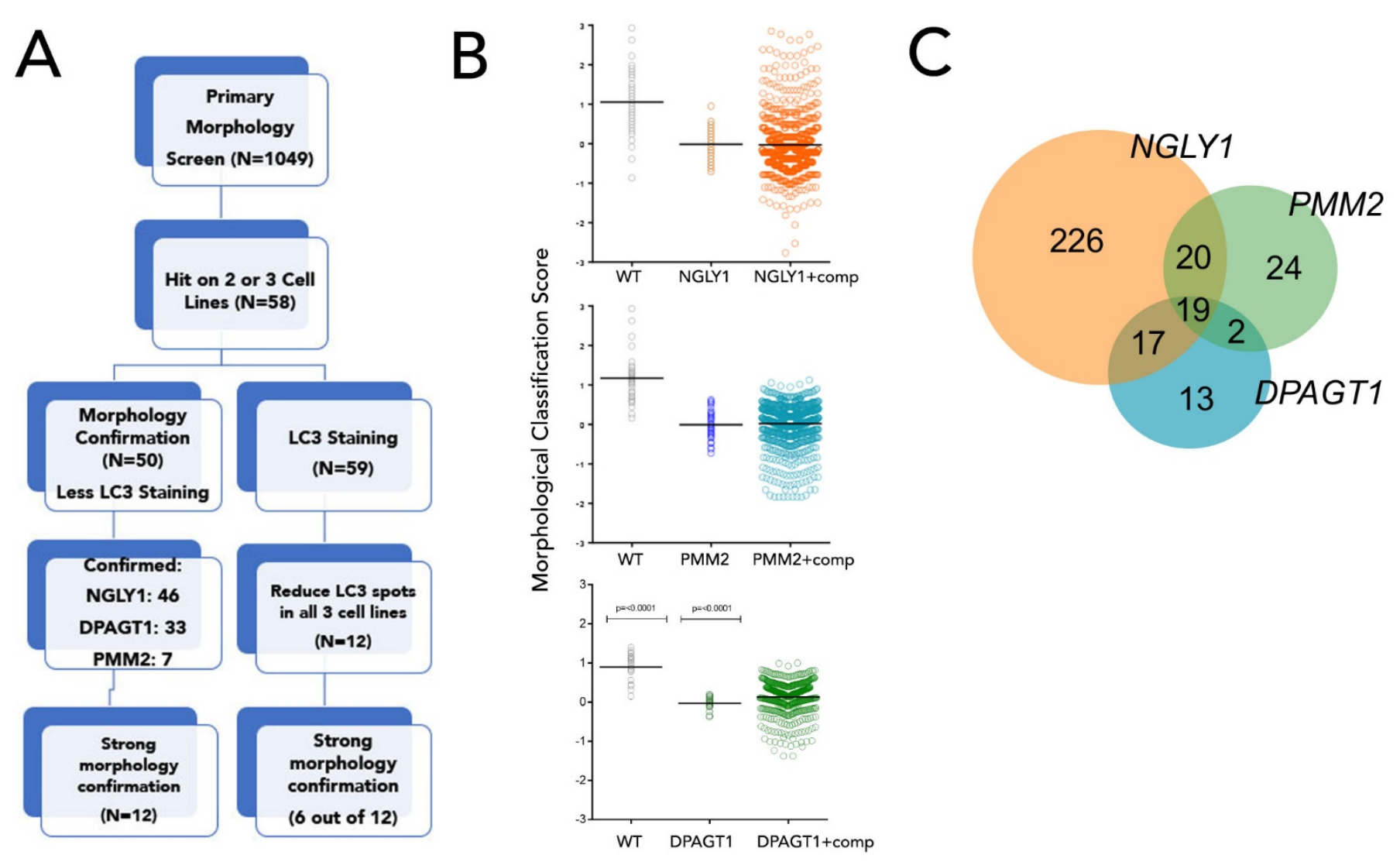

Figure 6. Primary screen identified compounds able to revert aberrant CDG and CDDG morphology phenotype. A, Screening workflow for selection of candidate compounds. B, Representative scatter plots of primary screen results for each genotype. Each dot represents one well. For RPE-1 and vehicle treated isogenic CDG and CDDG cell lines, $\mathrm{N}=56$ replicate wells. For compound treatments, each compound was tested in $\mathrm{N}=1$ well. C, Venn diagram comparing the number and overlap of compounds affecting each CDG/CDDG phenotype. 
Figure 7

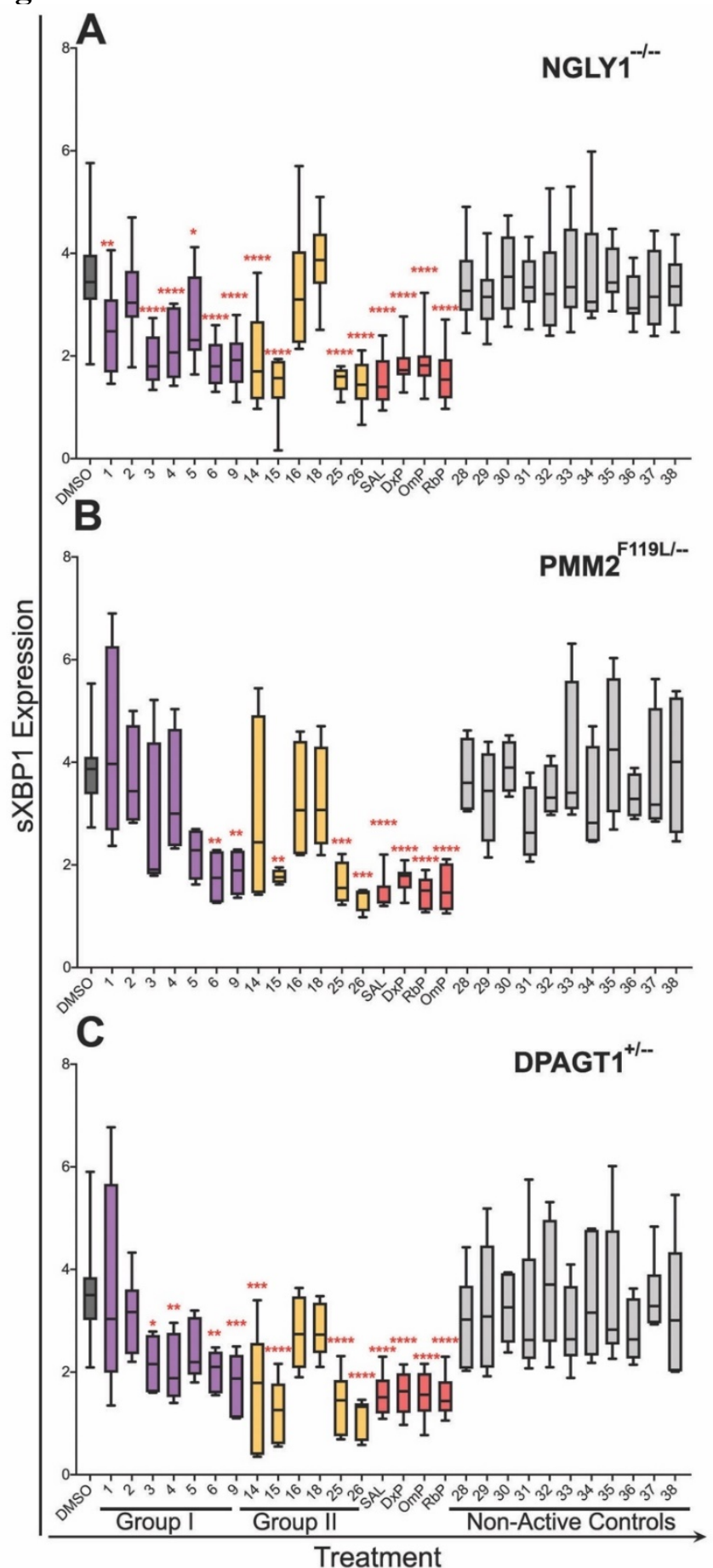

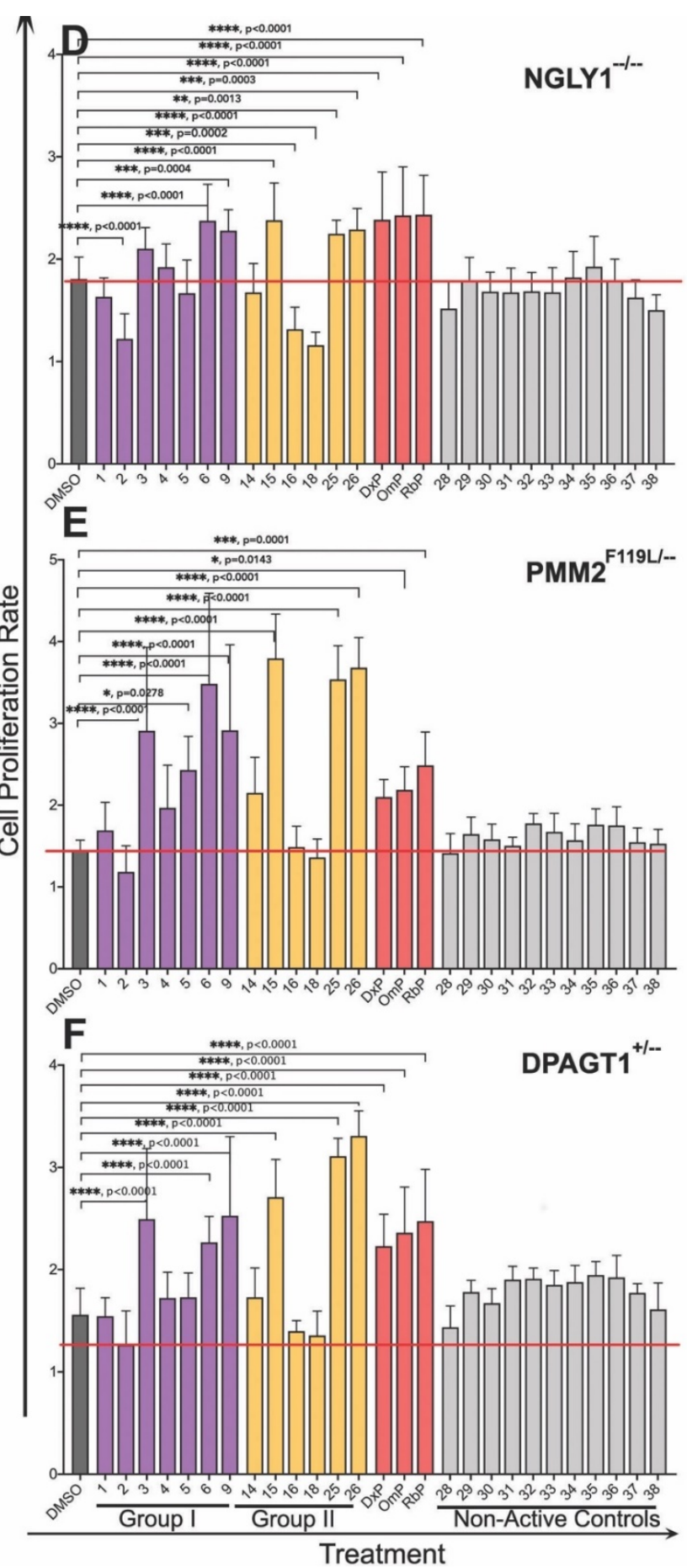

Treatment

Figure 7. Select active compounds are able to correct proliferation and/or ER stress phenotypes in the CDG and CDDG lines.

CDG and CDDG cell lines were treated with optimized concentrations of candidate and non-active control compounds and expression of $\mathrm{s} X B P 1$ and cell proliferation were assessed. A-C, Expression levels of $\mathrm{s} X B P 1$ in $N G L Y 1^{-/}$(A), $P M M 2^{F 119 L /-}$ (B), and $D P A G T 1^{+/-}$(C) clones treated with candidates, proton pump inhibitors (PPI; $\mathrm{DxP}, \mathrm{OmP}, \mathrm{RbB}$ ) or non-active compounds. Results are presented as a ratio of $\mathrm{s} X B P 1$ levels in compoundtreated cells to vehicle treated cells. D-F, Modulation of proliferation rate of $N G L Y 1^{-/}$(D), PMM2 $2^{F 19 L /-}$ (E), and $D P A G T 1^{+/-}(\mathrm{F})$ lines treated with candidates, PPIs, or non-active compounds. To define cell proliferation rate, ratio of $\mathrm{OD}_{590}$ at $72 \mathrm{hrs}$ to $\mathrm{OD}_{590}$ at $24 \mathrm{hrs}$ post seeding (before treatment) was calculated. Data presented are an average for all clones available for a specific mutation. $* *, \mathrm{P}<0.01, * * *, \mathrm{P}<0.001, * * * *, \mathrm{P}<0.0001$ 
Table 1.

Correlation between the proliferation and $\mathrm{s} X B P 1$ expression results in CDG and CDDG cell lines treated with candidate and non-active compounds, and PPIs. Statistical significance for $\mathrm{s} X B P 1$ changes and proliferation rates changes. * $\mathrm{P}<0.05, * *, \mathrm{P}<0.01, * * *, \mathrm{P}<0.001, * * * *, \mathrm{P}<0.0001$

\begin{tabular}{|c|c|c|c|c|c|c|c|}
\hline \multicolumn{2}{|c|}{ Compounds } & \multicolumn{2}{|c|}{$N G L Y 1^{-/-}$} & \multicolumn{2}{|c|}{$P M M 2^{\mathrm{F} 119 \mathrm{~L} /-}$} & \multicolumn{2}{|c|}{$D P A G T 1^{+/-}$} \\
\hline & Index & proliferation & $\mathrm{s} X B P 1$ & proliferation & $\mathrm{s} X B P 1$ & proliferation & $\mathrm{s} X B P 1$ \\
\hline \multirow{7}{*}{$\begin{array}{c}\text { Candidates } \\
\text { Group I }\end{array}$} & 1 & $\mathrm{~ns}$ & $* *$ & $\mathrm{~ns}$ & ns & $\mathrm{ns}$ & ns \\
\hline & 2 & $* * * *$ & ns & ns & ns & ns & ns \\
\hline & 3 & ns & $* * * *$ & $* * * *$ & ns & $* * * *$ & $*$ \\
\hline & 4 & ns & $* * * *$ & ns & ns & ns & $* *$ \\
\hline & 5 & $\mathrm{~ns}$ & $*$ & $*$ & ns & ns & ns \\
\hline & 6 & $* * * *$ & $* * * *$ & $* * * *$ & $* *$ & $* * * *$ & $* *$ \\
\hline & 9 & $* * *$ & $* * * *$ & $* * * *$ & $* *$ & $* * * *$ & $* * *$ \\
\hline \multirow{6}{*}{$\begin{array}{c}\text { Candidates } \\
\text { Group II }\end{array}$} & 14 & ns & $* * * *$ & ns & ns & ns & $* * *$ \\
\hline & 15 & $* * * *$ & $* * * *$ & $* * * *$ & $* *$ & $* * * *$ & $* * * *$ \\
\hline & 16 & $* * *$ & $\mathrm{~ns}$ & ns & ns & ns & ns \\
\hline & 18 & $* * * *$ & ns & ns & ns & ns & ns \\
\hline & 25 & $* *$ & $* * * *$ & $* * * *$ & $* * *$ & $* * * *$ & $* * * *$ \\
\hline & 26 & $* * *$ & $* * * *$ & $* * * *$ & $* * *$ & $* * * *$ & $* * * *$ \\
\hline \multirow{3}{*}{ PPIs } & DxP & $* * * *$ & $* * * *$ & $*$ & $* * * *$ & $* * * *$ & $* * * *$ \\
\hline & $\mathrm{OmP}$ & $* * * *$ & $* * * *$ & $* *$ & $* * * *$ & $* * * *$ & $* * * *$ \\
\hline & $\mathrm{RbP}$ & $* * * *$ & $* * * *$ & $* * * *$ & $* * * *$ & $* * * *$ & $* * * *$ \\
\hline \multirow{11}{*}{$\begin{array}{c}\text { Non-active } \\
\text { Controls }\end{array}$} & 28 & ns & $\mathrm{ns}$ & ns & ns & ns & ns \\
\hline & 29 & ns & ns & ns & ns & $\mathrm{ns}$ & ns \\
\hline & 30 & ns & ns & ns & ns & ns & ns \\
\hline & 31 & ns & ns & ns & ns & ns & ns \\
\hline & 32 & ns & ns & ns & ns & $\mathrm{ns}$ & ns \\
\hline & 33 & ns & ns & ns & ns & ns & ns \\
\hline & 34 & ns & ns & ns & ns & ns & ns \\
\hline & 35 & ns & ns & ns & ns & $\mathrm{ns}$ & ns \\
\hline & 36 & ns & ns & ns & ns & $\mathrm{ns}$ & ns \\
\hline & 37 & ns & ns & ns & ns & ns & ns \\
\hline & 38 & ns & $\mathrm{ns}$ & ns & ns & ns & ns \\
\hline
\end{tabular}

